\title{
S2 Table:
}

Contingency cell counts for imaging variables for a positive response to diagnostic injection of local anesthetic into the subacromial bursa. (For Table 4 in manuscript)

\begin{tabular}{|l|l|l|l|l|}
\hline Imaging variables & TP & FN & FP & TN \\
\hline All participants (n=180) & & & & \\
\hline SSp calcium (XR or USS) & 16 & 49 & 16 & 99 \\
\hline SSp calcium (XR) & 9 & 55 & 6 & 109 \\
\hline SSp calcium (USS) & 15 & 50 & 15 & 100 \\
\hline SSp FTT (USS) & 7 & 58 & 2 & 113 \\
\hline Age $\geq \mathbf{5 0}$ yrs (n= 49) & & & & \\
\hline SSp calcium (XR or USS) & 6 & 12 & 6 & 25 \\
\hline SSp calcium (XR) & 2 & 16 & 2 & 29 \\
\hline SSp calc (USS) & 6 & 12 & 5 & 26 \\
\hline SSp FTT (USS) & 5 & 13 & 2 & 29 \\
\hline Age < 50 yrs (n=131) & & & & \\
\hline SSp calcium (XR or USS) & 10 & 37 & 10 & 74 \\
\hline SSp calcium (XR) & 7 & 39 & 4 & 80 \\
\hline SSp calc (USS) & 9 & 38 & 10 & 74 \\
\hline SSp FTT (USS) & 2 & 45 & 0 & 84 \\
\hline Absevitions: (r)
\end{tabular}

Abbreviations: TP, true positives; FN, false negatives; FP, false positives; TN, true negatives; SSp, supraspinatus; XR, $x$ ray; USS, diagnostic ultrasound scan; FTT, full thickness tear.

Note: contingency cell counts may not total 180 due to missing data. 